\title{
Seguro de responsabilidad civil por daño medioambiental en España
}

\author{
Seguro de responsabilidade civil por dano ambiental na Espanha \\ César Teixeira', Fernando Pauletto ${ }^{2}$, Ana Paula Burin Fruet ${ }^{3}$, \\ Jackeline Karsten Kirinus ${ }^{4}$, Andrea Cristina Dörr ${ }^{5}$ \\ 'Universidade de Zaragoza - España \\ ${ }^{2}$ Universidade Anhanguera - Uniderp \\ ${ }^{3}$ Universidade Federal de Santa Maria - UFSM \\ ${ }^{4}$ Universidade do Oeste de Santa Catarina - UNOESC \\ 5Universidade Federal de Santa Maria - UFSM
}

\section{Resumen}

En este trabajo se analiza el seguro de responsabilidad civil por el daño medioambiental en España. Para ello, se analiza la Directiva 2004/35/ CE del Parlamento Europeo y del Consejo juntamente con la ley de responsabilidad civil medioambiental de España. Luego, se expone el concepto de seguro de responsabilidad civil y la estructura de la póliza de seguro. Y, finalmente se formulan unas breves consideraciones y las conclusiones.

Palabras clave: garantía, ley, medio ambiente, reparación.

\section{Resumo}

Neste trabalho se analisa o seguro de responsabilidade civil pelo dano ambiental na Espanha. Para tanto, se analisa a Diretiva 2004/35/CE do Parlamento Europeu e do Conselho em conjunto com a lei de responsabilidade civil ambiental da Espanha. Posteriormente, se expõe o conceito de seguro de responsabilidade civil e a estrutura da apólice de seguro. Por fim, se apresenta breves considerações e a conclusão. Palavras-chave: garantia, lei, meio ambiente, reparação. 


\section{INTRODUCCIÓN}

En materia de responsabilidad civil, una de las mayores dificultades de cualquier legislación es la tarea de garantizar el cumplimiento de las sentencias judiciales, con la efectiva reparación financiera del perjudicado.

Aunque las leyes disponen de instrumentos que aseguran el cumplimiento de la sentencia, la situación del perjudicado se complica cuando el responsable del daño no tiene como pagar el valor establecido en la sentencia.

Por eso, asegurar la reparación financiera del perjudicado frente a un daño judicialmente probado representa un desafío para el Derecho, pues una sentencia perfecta desde el punto de vista legal no tiene valor si no es efectiva. O sea, si a pesar de la condena el perjudicado permanece con el perjuicio financiero porque el responsable no puede hacer frente a su responsabilidad.

La tarea de garantizar el cumplimiento de la sentencia judicial escapa de la competencia del juez que la dictó, incluso de aquél "juez interesado" como ha mencionado Salvo Venosa, pues el juez sólo aplica la ley, si en la legislación no hay instrumentos para garantizar el derecho del perjudicado, nada se puede hacer.

En el caso de daño medio ambiental el problema que se plantea es aún más grave, porque su naturaleza difusa implica un daño también para la colectividad, la cual no puede quedarse en el perjuicio debido a la imposibilidad del responsable en recuperar el medioambiente dañado.

Además, frente a la posibilidad (que en realidad es un deber) de imponer sanciones administrativas, la Administración pública debe tener instrumentos para garantizar su cumplimiento.

\section{METODOLOGÍA}

Para escribir este trabajo se ha utilizado el Método Dedutivo, pues a través del estudio de la ley se investigó su aplicación en hechos concretos. También se ha utilizado el Método Comparativo con la finalidad de identificar diferencias y similitudes entre leyes que tratan del mismo tema.

Durante la investigación se ha utilizado principalmente la bibliografía indicada, la jurisprudencia y la ley.

${ }^{1}$ SALVO VENOSA (2005): p. 208.

\section{RESULTADOS Y DISCUSIÓN}

\section{I Seguro de responsabilidad civil en España}

La Directiva 2004/35/CE del Parlamento Europeo y del Consejo, de 21 de abril de 2004, es el primer texto legislativo de la Comunidad Europea que recoge el principio de política ambiental de que quien contamina paga. Establece un marco común sobre responsabilidad medioambiental en relación con la prevención y reparación de daños medioambientales.

El artículo $14.1^{2}$ de la Directiva determinó que los Estados miembros de la Unión Europea adoptasen alguna medida de garantía financiera para que los operadores (empresarios) pudiesen recorrer para hacer frente a sus responsabilidades, incluso en caso de insolvencia.

La Ley 26/2007, de 23 de octubre, transpone en el Derecho español la Directiva. Su objeto es regular la responsabilidad de los operadores de prevenir, evitar y reparar los daños medioambientales, de conformidad con el artículo 45 de la Constitución y con los principios de prevención y de que quien contamina paga (art. 1). Además, el objeto de la Ley 26/2007 es equipar España a otros países que pretenden que sea efectiva la reparación a los daños ambientales y superar la insuficiencia del sistema civil.

El artículo $24.1^{3}$ de la Ley 26/2007 obliga a los operadores de las actividades incluidas en el "Anexo III" " a disponer de una garantía financiera obligatoria.

La obligatoriedad de disponer de una garantía financiera tiene la finalidad de proteger a los terceros (en el caso del medio ambiente, la colectividad), garantizándoles un patrimonio para

\footnotetext{
${ }^{2}$ Artículo 14.1. Los Estados miembros adoptarán medidas para fomentar el desarrollo, por parte de los operadores económicos y financieros correspondientes, de mercados e instrumentos de garantía financiera, incluyendo mecanismos financieros en caso de insolvencia, con el fin de que los operadores puedan recurrir a garantías financieras para hacer frente a sus responsabilidades en virtud de la presente Directiva.

${ }^{3}$ Artículo 24. Constitución de una garantía financiera obligatoria. 1. Los operadores de las actividades incluidas en el Anexo III deberán disponer de una garantía financiera que les permita hacer frente a la responsabilidad medioambiental inherente a la actividad o actividades que pretendan desarrollar.

${ }^{4} \mathrm{El}$ "Anexo III" enumera las actividades profesionales consideradas peligrosas por la Ley 26/2007. Son así clasificadas porque por la naturaleza de su actividad es mayor el riesgo de que se produzca un daño ambiental y presentan un riesgo especial para la salud humana.
} 
hacer frente a la responsabilidad civil ${ }^{5}$.

En relación a las medidas de garantía obligatoria, la Ley 26/2007 fue más allá de la determinación de la Directiva y en su artículo 26 contempló tres modalidades de garantía financiera: subscripción de una póliza de seguro, obtención de un aval por una entidad financiera autorizada y constitución de una reserva técnica mediante la dotación de un fondo ad hoc.

En este estudio se aborda la modalidad de póliza de seguro prevista en el artículo 26.a.

\subsection{Concepto del seguro de responsabilidad civil}

El seguro surgió con la finalidad de evitar, o minorar, los efectos negativos de los hechos perjudiciales a los intereses de las personas. Su origen se relaciona con el concepto de mutualismo de la biología, en que la participación mutua de la comunidad proporciona la superación de las dificultades individuales ${ }^{6}$.

De acuerdo con el artículo 73 de la Ley 50/1980, de 8 de octubre (Ley del Contrato de Seguro): "Por el seguro de responsabilidad civil el asegurador se obliga, dentro de los límites establecidos en la Ley y en el contrato, a cubrir el riesgo del nacimiento a cargo del asegurado de la obligación de indemnizar a un tercero los daños y perjuicios causados por un hecho previsto en el contrato de cuyas consecuencias sea civilmente responsable el asegurado, conforme a derecho".

Esta definición legal no especifica mediante qué tipo de obligación el asegurador asume el riesgo, y esto es exactamente lo que diferencia el seguro de responsabilidad civil de las otras modalidades de seguro. En efecto, especificar el contenido de la obligación del asegurador podría dar lugar a una definición incompleta frente al alcance de la responsabilidad civil de los diferentes tipos de asegurados?

Por eso, para completar la definición del seguro de responsabilidad civil hay que acudir también los artículos 74 y 76 de la misma ley, que establecen, respectivamente, que el asegurador asumirá la dirección jurídica frente a la reclamación del perjudicado, y serán de su cuenta los gastos de defensa que se ocasionen; y que el derecho del tercero a exigir del asegurador el cumplimiento de la obligación de indemnizar y por consiguiente, la correspondiente obligación del asegurador de pagar al tercero cuando éste lo reclame.

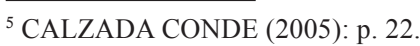

${ }^{6}$ LÚCIA PORCIONATO (2007): p. 50.

${ }^{7}$ CALZADA CONDE (2005): p.17.
}

Más allá de la delimitación de estos dos artículos, la póliza debe establecer de manera clara cuáles son las obligaciones del asegurador frente a la cobertura del riesgo. Normalmente el asegurador se obliga a pagar las eventuales indemnizaciones a terceros, los gastos de defensa y las fianzas ${ }^{8}$.

Otra peculiaridad del seguro de responsabilidad civil es que la prestación indemnizatoria tiene que ser a favor del tercero perjudicado, ajeno a la relación contractual. El derecho del tercero es una prestación patrimonial transmisible, tanto inter vivos como mortis causa, de modo que puede ser ejercitada por el tercero o sus herederos ${ }^{9}$.

\subsection{La estructura de la póliza del contrato de seguro}

Toda actividad económica o profesional implica una responsabilidad civil para el empresario, por eso tiene que gestionar los riesgos para minimizar las pérdidas y así maximizar los lucros de su empresa.

El daño ambiental es uno de los riesgos soportados por el empresario que explota una actividad económica, y puede serle reclamado a la propia empresa, constituyendo un riesgo empresarial. Sin embargo, para reducir o incluso evitar perjuicios para su empresa, el empresario puede optar por la prevención, el tratamiento o la cesión del riesgo a un asegurador. En este sentido, este riesgo empresarial puede ser transferido a una compañía aseguradora, por lo tanto, el daño al medio ambiente es un riesgo, en principio, asegurable ${ }^{10}$.

Como se ha mencionado, la finalidad de una garantía financiera, incluso a del seguro, es proteger a los terceros. Pero el seguro de responsabilidad civil tiene como principal finalidad cubrir el riesgo del responsable. Por lo tanto, el primer protegido es el responsable del daño, y en segundo lugar, por consecuencia, los terceros ${ }^{11}$.

El empresario tiene que elegir qué riesgos van a ser soportados por él como riesgo empresarial y qué riesgos van a ser transferidos a una compañía aseguradora, porque, como afirma Pavelek Zamora: "el seguro no ampara todo el conjunto de responsabilidades exigibles cuando se produce un daño o perjuicio imputable al asegurado, sino que las mismas se van perfilando en el propio contrato de seguro a través de los distintos pactos

\footnotetext{
${ }^{8}$ CALZADA CONDE (2005): p. 18.

${ }^{9}$ ZUBIRI DE SALINAS (2005): p. 63.

${ }^{10}$ ZUBIRI DE SALINAS (2005): pp. 52 y ss.

${ }^{11}$ CALZADA CONDE (2005): pp. 22 y ss.
} 
o secciones que conforman la póliza" 12 .

De esta forma, la póliza del contrato de seguro medio ambiental presenta la siguiente estructura: a) condiciones particulares; $b$ ) definiciones; c) objeto y alcance del seguro; d) exclusiones; y e) delimitaciones. A continuación se exponen los detalles de cada una:

\section{a) Las condiciones particulares}

E1 artículo 8 de la Ley 50/1980 establece los elementos mínimos que debe contener una póliza; estos elementos sirven para individualizar las partes contratantes y el riesgo objeto de la cobertura. Naturalmente tiene que constar en la póliza el nombre y apellidos de las partes contratantes con la designación del asegurado y beneficiario.

El concepto que se asegura en una póliza es el surgimiento de una obligación de reparar los daños ambientales causados por el ejercicio de alguna de las actividades relacionadas en el "Anexo III"; sin embargo, nada impide que empresas no incluidas en el anexo también contraten el seguro ${ }^{13}$.

La concepción de la naturaleza del riesgo cubierto es esencial para el contrato de seguro, porque sin riesgo no hay seguro ${ }^{14}$. Para Calzada Conde, el riesgo asegurable o cubierto es aquel que amenaza un interés del asegurado, que podría ser perjudicado por el ejercicio de reclamación, fundada o infundada, de responsabilidad civil por parte de un tercero ${ }^{15}$.

De acuerdo con el artículo 27 de la Ley 50/1980: "la suma asegurada representa el límite máximo de la indemnización a pagar por el asegurador en cada siniestro". Por lo tanto, el valor establecido como suma asegurada representa el límite de la cobertura del riesgo, es el valor máximo que el asegurador está obligado a pagar. La suma asegurada será fijada por la autoridad competente conforme métodos y criterios establecidos por el Reglamento de valoración de daños (artículo 24.3 de la Ley 26/2007). Por otro lado, la misma Ley, en su artículo 30, establece que la cobertura de la garantía financiera obligatoria nunca será mayor que 20.000.000 euros.

A pesar de este límite, el artículo 30.3 posi-

\footnotetext{
${ }^{12}$ PAVELEK ZAMORA, comentario sobre la necesidad del empresario elegir los riesgos que quiere asegurar, en LOZANO CUTANDA (2008): p. 340.

${ }^{13}$ PAVELEK ZAMORA, comentario sobre la posibilidad de empresas no incluidas en el "Anexo III" contratar un seguro, en LOZANO CUTANDA (2008): p. 343.

${ }^{14}$ Artículo 4 de la Ley 50/1980.

${ }^{15}$ CALZADA CONDE (2005): p. 37.
}

bilita el establecimiento de sublímites específicos para las obligaciones de prevención y evitación de daños, nunca inferiores al 10\% de la suma asegurada. Para Pavelek Zamora, es posible que estos límites sean ampliados a mayores cantidades ${ }^{16}$.

Para que el asegurador esté obligado a cumplir con su obligación es indispensable que el asegurado haga el pago de la prima, que es la contraprestación a la cobertura prestada por el asegurador. El pago de la prima es una condición para el cumplimiento de las clausulas de la póliza: aunque el contrato se haya perfeccionado, con el consentimiento manifestado por las partes contratantes y con la subscripción de la póliza, sus efectos materiales se retrasa hasta que la prima sé paga ${ }^{17}$.

El artículo 31.1 de la Ley 26/2007 establece la obligatoriedad de la constitución de la garantía desde la fecha en que surta efectos la autorización necesaria para el ejercicio de la actividad. Es decir, desde el inicio de la actividad el operador debe estar con la garantía constituida y debe mantenerse con ella durante todo el periodo de la actividad.

\section{b) Las definiciones}

En este punto las partes deben personalizar el contrato de seguro de acuerdo con la actividad asegurada y con los riesgos que se va a transferir a la compañía aseguradora. Es decir, las clausulas contractuales deben ser modeladas conforme a los intereses concretos de las partes: por eso, cuanto más especificadas sean las clausulas más pequeña será la posibilidad de que la relación entre asegurado y asegurador termine en litigio judicial.

Según Zubiri de Salinas, los contratos de seguro de protección del medio ambiente contemplan una categoría de cláusulas conocida en la práctica como condiciones especiales, las cuales hacen referencia a una determinada modalidad de contrato en función de la cobertura concreta (contaminación repentina, contaminación gradual, combinado de contaminación) o de un tipo de actividad (actividades itinerantes, estaciones de servicio, vertederos, transporte terrestre controlado por el asegurado) ${ }^{18}$.

Además, deben constar en la póliza aquellas expresiones propias de la legislación medioambiental, que escapan de la terminología habitual. Como la Ley 26/2007 no detalla el concepto de contaminación, es muy importante que la póliza incluya su concepto, porque no todos los contratos otorgan

\footnotetext{
${ }^{16}$ PAVELEK ZAMORA, en el comentario al artículo 30.3 de la Ley 26/2007, en LOZANO CUTANDA (2008): p. 344.

${ }^{17}$ ZUBIRI DE SALINAS (2005): pp. 276 y ss.

${ }^{18}$ ZUBIRI DE SALINAS (2005): pp. 200 y ss.
} 
coberturas a todos los daños al medio ambiente, sólo aquellos daños causados por contaminación ${ }^{19}$.

\section{c) El objeto y alcance del seguro}

Conforme el artículo 1 de la Ley 50/1980, el asegurador se obliga a indemnizar en la exacta medida del riesgo objeto de la cobertura del contrato de seguro de responsabilidad civil.

Como se ha mencionado, no todos los riesgos son asegurables, por eso es necesario hacer la individualización del riesgo a través de la declaración del riesgo por parte del proponente de seguro. Esta individualización es de suma importancia, pues es la materialización de la obligación que será soportada por el asegurador, motivo por el cual tiene que estar delimitada en la póliza ${ }^{20}$.

Tratándose de responsabilidad civil medio ambiental, el contenido de la garantía tiene que observar el artículo $29^{21}$ de la Ley 26/2007, de modo que el objeto y alcance del seguro con cobertura mínima debe asegurar los costes de prevención y evitación referidos en el artículo 17 y los costes de reparación descritos en los artículos 19 y 20, hasta el límite de la suma asegurada. Además, el hecho dañoso a prevenir, limitar o reparar ha de ser originado por contaminación ${ }^{22}$.

Es importante mencionar también que la reparación de los daños por el asegurador se limita a las medidas que se encuadren en el concepto de reparación primaria (art. 29.b).

\section{d) Las exclusiones}

El artículo 32.2 de la Ley 26/2007 establece que el hecho generador de la garantía es la contaminación que se produzca de forma accidental y aleatoria, o sea, extraordinaria.

Para Hebrero Álvarez, accidental significa que la contaminación proviene de un hecho de

\footnotetext{
${ }^{19}$ PAVELEK ZAMORA, comentario sobre la importancia de la póliza traer el concepto de contaminación, en LOZANO CUTANDA (2008): p. 347. ${ }^{20}$ HARTEN FILHO (2007): pp. 36 y ss.

${ }^{21}$ Artículo 29. Costes cubiertos.

El contenido de la garantía que se preste a través de las modalidades contempladas en el artículo 26 deberá contemplar la cobertura de los siguientes costes:

a. Los derivados de las obligaciones del operador reguladas en el artículo 17

b. Los derivados de las obligaciones del operador reguladas en los artículos 19 y 20. En la medida que dichos daños afecten a las aguas, a las especies silvestres y a sus hábitats o a las riberas del mar y de las rías, los gastos garantizados se limitan a los encuadrados dentro del concepto de reparación primaria definido en el apartado 1.a del Anexo II.

22 PAVELEK ZAMORA, en el comentario al artículo 29 de la Ley 26/2007, en LOZANO CUTANDA (2008): p. 348.
}

carácter extraordinario y no como una consecuencia normal o prevista de la actividad que se realiza en la industria asegurada. Además, de ninguna manera la contaminación ha de ser causada de forma intencionada ${ }^{23}$.

El artículo 32.2 indica las causas que excluyen la garantía.

\section{e) Las delimitaciones}

Las delimitaciones presentes en la póliza tienen que ver con el ámbito temporal y territorial de cobertura del seguro por una compañía aseguradora.

En el primer caso, las divergencias ocurren debido a las peculiaridades del daño medio ambiental, pues muchísimas veces el momento de producción del siniestro no coincide con el momento de la manifestación del siniestro y estos dos, a su vez, tampoco coinciden con el momento de reclamación del siniestro. El problema es mayor en aquellos casos en que la industria cambia de aseguradora con asiduidad, de forma que la omisión de cláusulas temporales en la póliza puede originar la descobertura del siniestro ${ }^{24}$.

Para resolver esta cuestión, el artículo 32.1 de la Ley 26/2007 presenta una solución distinta de la regla general contemplada en el artículo 73.2 de la Ley 50/1980. Así, se puede limitar el ámbito temporal de la garantía, de forma que queden incluidas aquellas responsabilidades en las que se den conjuntamente las siguientes circunstancias:

I. Que el comienzo de la emisión causante de la contaminación o bien el comienzo de la situación de riesgo inminente de contaminación sea identificado y se demuestre que ha ocurrido dentro del periodo de la garantía.

II. Que la primera manifestación constatable de la contaminación se haya producido dentro del periodo de la garantía o dentro del plazo de tres años a contar desde la terminación de la misma. Se entiende por primera manifestación el momento en que se descubra por primera vez la existencia de una contaminación, tanto si entonces se considera peligrosa o dañina como si no es así.

III. Que la reclamación al operador por la contaminación haya tenido lugar dentro del periodo de garantía o dentro del plazo de tres años a contar desde la terminación de la misma.

\footnotetext{
${ }^{23}$ HEBRERO ÁLVAREZ (2002): p. 205.

${ }^{24}$ HEBRERO ÁlVAREZ (2002): pp. 214 y ss.
} 
Por lo tanto, en comparación con la regla general, la Ley 26/2007 establece un plazo de garantía más amplio.

En el segundo caso, en relación a la delimitación territorial de la garantía, la Ley 26/2007 no hace referencia, pero parece razonable entender, como afirma Pavelek Zamora ${ }^{25}$, que deberá circunscribirse "a daños que tengan origen en actividades desarrolladas en territorio español y que causen daños en España" 26 .

\section{Fondo de compensación de daños medioambientales del Consorcio de Compensación de Seguros}

Los operadores que optan por contratar un seguro como modalidad de garantía financiera cuentan también con un Fondo de compensación de daños medioambientales. Este Fondo es administrado y gestionado por el Consorcio de Compensación de Seguros, una entidad autónoma bajo la supervisión del Ministerio de Economía y Hacienda, que se constituye con las aportaciones de los operadores asegurados mediante un recargo sobre la prima del seguro (art. 33.1 de la Ley $26 / 2007$ ).

Una de las finalidades de este Fondo es prolongar la responsabilidad asegurada en la póliza original, de modo que aquellos daños causados por las actividades autorizadas durante la vigencia del seguro y que se manifiesten o se reclamen después del transcurso de los plazos de manifestación o reclamación admitidos en la póliza no queden sin cobertura. Sin embargo, sólo es posible acudir esta cobertura prolongada si la reclamación se hace como máximo de un número de años igual a aquel de vigencia de la póliza de seguro, desde su término y con el límite de 30 años (art. 33.1.II de la Ley 26/2007).

La otra finalidad de este Fondo es responder cuando la aseguradora elegida por el operador sea insolvente (art. 33.2 de la Ley 26/2007).

\footnotetext{
${ }^{25}$ PAVELEK ZAMORA, comentarios sobre la delimitación territorial de la garantía, en LOZANO CUTANDA (2008): p. 352.

${ }^{26}$ Por otro lado, si una industria española causa daño a un Estado miembro de la Unión Europea, se debe acudir a la regla del artículo 8.2.d de la Ley 26/2007, conforme al cual: "el Ministerio de Medio Ambiente, en colaboración con la autoridad competente afectada y a través del Ministerio de Asuntos Exteriores y de Cooperación, tomará las medidas necesarias para que los operadores responsables del daño medioambiental o amenaza inminente de daño asuman los costes que hayan ocasionado a las autoridades competentes de los Estados miembros afectados con sujeción a los criterios de reciprocidad que se establezcan en Tratados internacionales o en la normativa de dichos Estados.
}

Más allá de resolver los problemas de insolvencia de las aseguradoras y de los problemas de ámbito temporal de las pólizas, el Fondo puede ser una solución para los supuestos en que no se puede probar el nexo causal, como en los casos en que la víctima sólo puede identificar grupos de posibles responsables, pero no al responsable concreto por causar el daño ${ }^{27}$.

\section{Fondo estatal de reparación de daños medioambientales}

La Ley 26/2007 crea en el artículo 34 un Fondo estatal de reparación de daños medioambientales, que actúa como complemento al sistema de garantías financieras exigidas por la misma ley. Es gestionado por el Ministerio del Medio Ambiente y financiado con recursos procedentes de los Presupuestos Generales del Estado (art. 34.1.II).

Este Fondo se destina a sufragar los costes derivados de medidas de prevención, de evitación o de reparación de los bienes de dominio público de titularidad estatal, pero sólo aquellos bienes que se relacionan con el artículo $7.3^{28}$, en aquellos supuestos en los que sean de aplicación las causas de inexigibilidad de la obligación de sufragar los costes regulados en los artículos 14.2 y 15.2 (art. 34.1).

En realidad, el ámbito de operación del Fondo está en el artículo 14.2. Por este artículo, el operador no estará obligado a sufragar el coste imputable a aplicación de las medidas reparadoras cuando demuestre que no ha incurrido en culpa, dolo o negligencia y aun demuestre una de las circunstancias mencionadas en los apartados "a" y "b".

De esta forma, cuando no se consigue probar la responsabilidad civil del autor del daño medioambiental el Fondo estatal sufraga el coste de las medidas reparadoras del medio ambiente dañado.

\section{El Pool Español de Riesgos Medioambientales}

El aseguramiento de los riesgos medio ambientales plantea también un gran riesgo para las aseguradoras.

\footnotetext{
${ }^{27}$ RUDA GONZÁLEZ (2008): pp. 541 y ss.

${ }^{28}$ Artículo 7. Competencias administrativas.

3. Cuando, en virtud de lo dispuesto en la legislación de aguas y en la de costas, corresponda a la Administración General del Estado velar por la protección de los bienes de dominio público de titularidad estatal y determinar las medidas preventivas, de evitación y de reparación de daños, aquella aplicará esta Ley en su ámbito de competencias.
} 
En este sentido, para que una aseguradora pueda asegurar riesgos medio ambientales es necesaria la previa autorización administrativa del Ministro de Economía y Hacienda y la inscripción en el registro administrativo llevado por la Dirección General de Seguros y Fondos de Pensiones. Además, estas aseguradoras están sometidas a control por parte de la Dirección General de Seguros y Fondos de Pensiones en relación a los márgenes de solvencia y demás previsiones técnicas ${ }^{29}$.

De acuerdo con el artículo 13.a del Real Decreto Legislativo $6 / 2004^{30}$, de 29 de octubre, para que una aseguradora pueda operar en el ramo de la responsabilidad civil tiene que tener un capital social y fondo mutual mínimo de 9.015.181,57 euros.

De esta forma, las dificultades involucradas en el aseguramiento de los riegos medio ambientales han dado lugar a la creación de asociaciones o pools, con la finalidad de facilitar la necesaria capacidad económica y permitir a las aseguradoras el aseguramiento de riesgos medio ambientales ${ }^{31}$.

El Pool Español de Riesgos Medioambientales, que fue constituido en 1994, es una agrupación de interés económico constituida para administrar un convenio de correaseguro para la suscripción conjunta de los riegos medioambientales. Está integrada por 25 compañías (17 compañías de seguro directo y 8 compañías reaseguradoras ${ }^{32}$.

\section{CONCLUSIONES}

Como se ha demostrado a lo largo de este trabajo, la preocupación por la protección del medio ambiente no tiene fronteras, más allá de acciones concretas y de las políticas públicas implementadas para la preservación del medio ambiente, queda evidente la importante función del Derecho.

Dentro del Espacio Europeo, la Directiva 2004/35/CE del Parlamento Europeo y del Consejo, de 21 de abril de 2004, establece importantes directrices de protección y de responsabilidad civil medio ambiental para los países de la Unión Europea.

La Ley 26/2007 sigue la Directiva en muchos puntos. En relación a las garantías finan-

\footnotetext{
${ }^{29}$ ZUBIRI DE SALINAS (2005): pp. 191 y ss.

${ }^{30}$ Por el que se aprueba el texto refundido de la Ley de ordenación y supervisión de los seguros privados (BOE 5.11.2004).

${ }^{31}$ HEBRERO ÁLVAREZ (2002): p. 181.

${ }^{32}$ Relación de entidades miembros en el año 2011. Disponible en: <http:/ /www.perm.es/fr-info-ins.htm>. Acceso en 3 junio de 2012.
}

cieras fue más allá de la exigencia de la Directiva y ha contemplado tres modalidades, ofreciendo más opciones para los operadores. Además, recoge instrumentos modernos para prevenir y sobre todo para reparar los daños medio ambientales.

En este sentido, más allá que identificar y responsabilizar el autor del daño, es importante ocuparse de la recuperación del medio ambiente dañado. Hay que pensar en la posibilidad del operador quedarse insolvente, lo que imposibilitaría la reparación del medio ambiente dañado, aunque haya una sentencia condenatoria. $\mathrm{O}$, incluso, en aquellos casos en que el responsable queda exonerado de la obligación.

La Ley 26/2007 ha pensado en estas situaciones: la obligatoriedad de los operadores del "Anexo III" de disponer de una garantía financiera, el Fondo de compensación de daños medioambientales del Consorcio de Compensación de Seguros y el Fondo estatal de reparación de daños medioambientales son instrumentos que posibilitan la recuperación del medio ambiente dañado aunque el operador responsable por el daño no tenga condiciones financieras para ello.

Estas alternativas tienen la finalidad de reparar el medio ambiente y también preservar el derecho de la colectividad a un medio ambiente saludable. Por eso, uno de los puntos más importantes de la Ley española es su preocupación con la reparación del medio ambiente dañado.

\section{REFERENCIAS}

CALZADA CONDE, M. Á. El seguro de responsabilidad civil. Navarra: Aranzadi. 2005. 155 pp.

ESPAÑA. Directiva 2004/35/CE del Parlamento Europeo y del Consejo, de 21 de abril de 2004. Disponible en: <http://eur-lex. europa.eu/LexUriServ/LexUriServ.do?uri $=\mathrm{O}$ $\mathrm{J}: L: 2004: 143: 0056: 0075:$ es:PDF>. Acceso en: 30 abr. 2012.

ESPAÑA. Noticias Jurídicas. Base de datos de legislación, Ley 50/1980, de 8 de octubre. Disponible en: <http://noticias.juridicas.com/base_datos/Privado/150-1980.html>. Acceso en: 20 may. 2012.

ESPAÑA. Noticias Jurídicas. Base de datos de legislación, Ley 26/2007, de 23 de octubre. Disponible en: $<$ http://noticias.juridicas.com/base_datos/ Admin/126-2007.html>. Acceso en: 30 abr. 2012. 
ESPAÑA. Noticias Jurídicas. Base de datos de legislación, Real Decreto Legislativo 6/2004, de 29 de octubre. Disponible en: <http://noticias.juridicas.com/base_datos/Privado/rdleg6-2004.html>. Acceso en: 30 may. 2012.

HARTEN FILHO, C. A. El deber de declaración del riesgo en el contrato de seguro, exposición crítica del modelo brasileño y estudio del derecho comparado. Salamanca: Ratio Legis. 2007. 153 pp.

HEBRERO ÁLVAREZ, J. I. El aseguramiento de la responsabilidad civil por daños al medio ambiente. Madrid: Dykinson. 2002. 305 pp.

LÚCIA PORCIONATO, A.; MENDES LOBO, A. A vez do seguro ambiental: o fomento às novas coberturas pelas inovações da lei complementar $\mathrm{n}^{\circ} 126$, de 16.01.2007. Revista IOB de Direito Civil e Processual Civil, Porto Alegre, Síntese. 2007. p. 46-91.

LOZANO CUTANDA, B. (Coord.). Comentarios a la ley de responsabilidad medio ambiental. Pamplona: Aranzadi. 2008. 554 pp.

RUDA GONZÁLEZ, A. El daño ecológico puro La responsabilidad civil por el deterioro del medio ambiente, con especial atención a la Ley 26/2007, de 23 de octubre, de responsabilidad medioambiental. Pamplona: Aranzadi. 2008. 709 pp.

SALVO VENOSA, S. de. Direito civil: responsabilidade civil, São Paulo: Atlas. 5 ed. 2005. 368 pp.

ZUBIRI DE SALINAS, M. El seguro de responsabilidad civil por daños al medio ambiente. Navarra: Aranzadi. 2005. 311 pp. 